\title{
Seeking Forgiveness: Factor Structure in Samples from Latin America, Africa, Asia, and Southern Europe
}

Petición de perdón: estructura factorial en muestras de América Latina, África, Asia y Europa del Sur

Recibido: mayo 10 de 2012 | Revisado: agosto 5 de 2012 | Aceptado: agosto 20 de 2012

\author{
FELIX NeTO* \\ University of Oporto, Portugal \\ ETIENNE MULLET** \\ Institute of Advanced Studies (EPHE), France \\ StePhanie ChIARAMEllo *** \\ University of Montreal, Canada \\ Chritiany SuWARTONO ***** \\ Atma Jaya Catholic University, Indonesia
}

doi:10.11144/Javeriana.UPSY12-3.sffs

Para citar este artículo: Neto, F., Mullet, E., Chiaramello, S., \& Suwartono, C. (2013). Seeking forgiveness: Factor structure in samples from Latin America, Africa, Asia, and Southern Europe. Universitas Psychologica, 12(3), 663-669. doi:10.11144/ Javeriana.UPSY12-3.sffs

University of Oporto, Portugal. Email: fneto@ fpce.up.pt

*** Institute of Advanced Studies (EPHE), France. Email:mullet@univ-tlse2.fr

**** University of Montreal, Canada. Email: stephanie. chiaramello@umontreal.ca

***** Atma Jaya Catholic University, Indonesia Email: octoelf_82@yahoo.com

\begin{abstract}
A B S T R A C T
The study examined, using confirmatory factor analyses, the three-factor structure of the Disposition to Seek Forgiveness Questionnaire - inability in seeking forgiveness, sensitivity to circumstances before seeking forgiveness, and unconditional seeking of forgiveness - among samples from Latin America (Brazil), Africa (Angola and Mozambique), Asia (Indonesia), and Southern Europe (Portugal). It was found that this ternary structure has cross-cultural generality.

Key words authors

Seeking forgiveness, Angola, Brazil, Indonesia, Mozambique.

Key words plus

Factor Analyses, Social Psychology, Quantitative Research.

\section{RESUMEN}

El estudio examinó la estructura factorial del Disposition to Seek Forgiveness Questionnaire a través del análisis factorial confirmatorio -incapacidad de pedir perdón, sensibilidad a las circunstancias antes de pedir perdón y petición incondicional de perdón- en muestras de América Latina (Brasil), África (Angola y Mozambique), Asia (Indonesia) y Europa del Sur (Portugal). En cada una de las muestra se encontró la misma estructura de tres factores. Palabras clave autores

Pedir perdón, Angola, Brasil, Indonesia, Mozambique.

Palabras clave adicionales

Análisis factorial, psicología social, investigación cuantitativa.
\end{abstract}




\section{Introduction}

The disposition to seek forgiveness has recently been examined (Basset, Basset, Lloyd, \& Johnson, 2006; Chiaramello, Munoz Sastre, \& Mullet, 2008), and a three-factor structure has been found, which closely paralleled similar factors that have been found regarding the willingness to grant forgiveness, also called forgivingness (Roberts, 1995). In the study by Chiaramello et al. (2008), the first factor was called inability in seeking forgiveness (ISF, e.g., I don't feel able to seek forgiveness even when I think that I am entirely responsible for the harm done). This factor was close to the "hardness of heart" factor suggested in Basset et al. (2006). It was linked with trait-anger, paranoid tendencies (that are components of neuroticism), lack of agreeableness and openness, orientation to the past and self-punishment tendencies. It was also strongly linked with dispositional lasting resentment, a factor that is part of the forgivingness construct (see, Mullet et al., 2003).

The second factor was called sensitivity to circumstances (before seeking or not seeking forgiveness, SCS). This factor encompassed the "speaking the truth" factor suggested by Basset et al. (2006); that is, both factors were about the circumstances of the offense (e.g., I feel it is easier to seek forgiveness when the harm done has clearly visible consequences for the person I have harmed). Sensitivity to circumstances was linked with cynicism and paranoid tendencies. This factor was strongly linked with the sensitivity to circumstances factor before forgiving that is also part of the forgivingness construct. Finally, the third factor was called unconditional seeking of forgiveness (USF, e.g., My worldviews lead me to always seek forgiveness). This factor was close to the "seeking forgiveness" factor suggested in Basset et al. (2006). It was mainly linked with agreeableness, and with orientation to the future. It was also strongly and positively linked to unconditional forgiveness, and moderately and negatively linked with lasting resentment, two components of the forgivingness structure.

Previously, this three-factor structure has only been found in two Western European samples of adults from various ages (Chiaramello et al., 2008) and in one Northern American sample of students (Basset et al., 2006). The present study examined whether this three-factor structure also holds in samples from other parts of the world: Latin America (Brazil), Africa (Angola and Mozambique), Asia (Indonesia), and Southern Europe (Portugal).

Regarding Portugal, we had good reasons to think that the three-factor structure would hold. Previous studies conducted with Portuguese samples have found the three-factor forgivingness structure (Mullet et al., 2003; Neto, 2007; Neto \& Mullet, 2004). As the two three-factor structures - forgivingness and the disposition at seeking forgiveness - are parallel structures, it seemed to be likely that a three-factor structure should also be evidenced among Portuguese participants.

Regarding Brazil, and although no previous study on forgivingness has been conducted in this country, it also seemed likely that the three-factor structure should be found, since, on the cultural level, Brazil and Portugal share many common characteristics. In addition, one study on the conceptualizations of forgiveness that was conducted in Latin America (Bagnulo, Muñoz-Sastre, \& Mullet, 2009) showed that Latin Americans, unsurprisingly, conceptualized forgiveness in basically the same way as Europeans. Regarding Indonesia, the same reasoning as the one developed for Portugal and Brazil should apply. Suwartono, Prawasti, and Mullet (2007) have shown that, among the Indonesians, the three-factor forgivingness structure can be found.

By contrast, regarding Angola and Mozambique, there was uncertainty about the possibility to replicate the three-factor seeking forgiveness structure. In a study conducted on Congolese participants, Kadima Kadiangandu, Mullet, and Vinsonneau (2001) found a reduced two-factor forgivingness structure. However, in a subsequent study on the conceptualizations of forgiveness, which was conducted on a similar sample (Kadima Kadiangandu, Gauché, Vinsonneau, \& Mullet, 2007), the structure of conceptualizations that was found was identical to the one evidenced in Europe and in Latin America. As a result, in the African 
samples, in addition to examining the structure of the disposition to seek forgiveness, we decided to also re-examine the structure of forgivingness.

In summary, (a) our first hypothesis was that the three-factor structure suggested by Chiaramello et al. (2008) should hold in the samples from Brazil, Indonesia and Portugal, and (b) our second hypothesis was that the pattern of associations relationships shown in Chiaramello et al. (2008) between the disposition to seek forgiveness structure and the forgivingness structure should also be found in the present study. In addition, we wondered whether the three-factor disposition to seek forgiveness structure and the three-factor forgivingness structure would both hold in the African sample.

\section{Method}

\section{Participants}

The total number of participants was $896(559$ females and 337 males): 148 Angolans, 171 Brazilians, 214 Indonesians, 112 Mozambicans, and 251 Portuguese. They were all students, and their mean age was $22.5(S D=4.5)$. They were all unpaid volunteers and recruited on the campus of their universities by research assistants who were students of psychology trained in data-gathering techniques using questionnaires.

\section{Materials}

The first questionnaire was the Disposition to Seek Forgiveness Questionnaire (Chiaramello et al., 2008). It was composed of 15 items (see Table 1). An 11-point scale was printed following each item. The two extremes of the scales were labeled Disagree completely and Completely agree. The second questionnaire was the Forgivingness Questionnaire (Mullet et al., 2003). It was composed of 15 items, five items for the Lasting Resentment scale (e.g., I keep being resentful even if the offender has begged for forgiveness), five items for the Sensitivity to circumstances scale (e.g., I forgive more easily if my family or friends have invited me to do so), and five items for the Unconditional Forgiveness scale (e.g., I can easily forgive even if the harm was intentional). The third questionnaire was the Forgiveness Likelihood scale (Rye et al., 2001). Participants were also asked about their level of religious involvement (not believer in God, believer but not regular attendee, regular attendee to a church, temple or mosque).

\section{Procedure}

Each participant answered individually in a quiet room at the university (the more frequent procedure). Two versions of the questionnaires were used that only differed in item order (direct or inverse). The experimenter was, in most cases, present when the participants filled in the questionnaires. It took approximately 30 minutes to complete the questionnaires. Owing to a lack of time, the Forgivingness Questionnaire and the Forgiveness Likelihood scale were not presented to the Indonesian students.

\section{Results}

A series of four confirmatory analyses were conducted on the 15 items from the Disposition to Seek Forgiveness Questionnaire, that is, one analysis for each continent. Detailed results are shown in Table 1. In all cases the fit indices were judged satisfactory. Namely, the RSMEA values were always equal to 0.08 or lower.

Regarding ISF, the mean values were close from one sample to another, ranging from 1.48 to 2.47. Sheffé tests indicated that the only significant difference was between Brazil and Portugal, $p<0.001$. Regarding SCS, the mean values were not as close as it was the case for ISF, ranging from 3.69 to 6.78 . The Indonesian score significantly differed from each of the other scores, $p<0.001$. When a correction for acquiescence, estimated from Suwartono et al. (2007) data, was applied on the Indonesian data, these differences remained significant. Regarding USF, the mean values ranged from 5.66 to 7.71 . The Indonesian score significantly differed from each of the other scores, $p<0.001$. When a correction was applied on the Indonesian data, these differences were no longer significant. 


\section{TABLE 1}

The results of the confirmatory factor analyses conducted on the 15 items from the Disposition to Seek Forgiveness Questionnaire for each of the four samples and for the overall data set

\begin{tabular}{|c|c|c|c|c|c|}
\hline Items & $\mathrm{AM}$ & B & I & $\mathbf{P}$ & $\mathrm{O}$ \\
\hline \multicolumn{6}{|l|}{ Inability in Seeking Forgiveness } \\
\hline $\begin{array}{l}\text { I don't feel able to seek forgiveness even when I feel guilty about the harm } \\
\text { done. }\end{array}$ & 0.71 & 0.84 & 0.72 & 0.76 & 0.73 \\
\hline ... even when I have a positive opinion of the person I have harmed. & 0.69 & 0.82 & 0.49 & 0.9 & 0.73 \\
\hline ...even when I think I am entirely responsible for the harm done. & 0.61 & 0.93 & 0.77 & 0.86 & 0.78 \\
\hline ...even when the consequences of the harm have disappeared. & 0.52 & 0.87 & 0.54 & 0.7 & 0.65 \\
\hline ...even if my family or my friends have invited me to do so & 0.6 & 0.82 & 0.82 & 0.68 & 0.71 \\
\hline$M$ & 1.85 & 2.47 & 1.9 & 1.48 & 1.87 \\
\hline SD & 2.06 & 2.59 & 1.48 & 1.69 & 1.98 \\
\hline alpha & 0.76 & 0.93 & 0.8 & 0.88 & 0.84 \\
\hline \multicolumn{6}{|l|}{ Sensitivity to Circumstances } \\
\hline $\begin{array}{l}\text { I feel it is easier to seek forgiveness when it does not put me in a position of } \\
\text { inferiority vis-à-vis the person I have harmed. }\end{array}$ & 0.54 & 0.65 & 0.48 & 0.62 & 0.63 \\
\hline $\begin{array}{l}\text {...when the harm done has clearly visible consequences for the person I have } \\
\text { harmed. }\end{array}$ & 0.53 & 0.62 & 0.45 & 0.37 & 0.5 \\
\hline ...when my family or friends have encouraged me to do so. & 0.54 & 0.71 & 0.65 & 0.77 & 0.71 \\
\hline ... when I feel good and everything is going well. & 0.52 & 0.68 & 0.68 & 0.65 & 0.65 \\
\hline ...when the person I have harmed is much older than me. & 0.54 & 0.55 & 0.59 & 0.68 & 0.67 \\
\hline M & 4.16 & 4.32 & 6.78 & 3.69 & 4.68 \\
\hline SD & 2.55 & 2.48 & 2.02 & 2.3 & 2.63 \\
\hline alpha & 0.8 & 0.78 & 0.71 & 0.75 & 0.77 \\
\hline \multicolumn{6}{|l|}{ Unconditional Seeking of Forgiveness } \\
\hline I readily seek forgiveness even when I feel bad and everything is going badly. & 0.66 & 0.57 & 0.89 & 0.46 & 0.66 \\
\hline ...even when I have already been punished for the harm done. & 0.64 & 0.66 & 0.53 & 0.64 & 0.66 \\
\hline My worldviews lead me to always seek forgiveness. & 0.6 & 0.63 & 0.55 & 0.54 & 0.63 \\
\hline $\begin{array}{l}\text {...even when I feel that it puts me in a position of inferiority vis-à-vis the } \\
\text { person I have harmed. }\end{array}$ & 0.75 & 0.78 & 0.67 & 0.8 & 0.73 \\
\hline ...even when the harm done has no visible consequences. & 0.75 & 0.83 & 0.56 & 0.72 & 0.67 \\
\hline M & 6.49 & 5.67 & 7.71 & 5.66 & 6.39 \\
\hline SD & 2.64 & 2.34 & 1.59 & 2.23 & 2.39 \\
\hline alpha & 0.79 & 0.82 & 0.77 & 0.77 & 0.8 \\
\hline GFI & 0.94 & 0.88 & 0.88 & 0.9 & 0.94 \\
\hline CFI & 0.95 & 0.93 & 0.87 & 0.92 & 0.92 \\
\hline $\mathrm{Chi}^{2}$ & 124 & 176 & 212 & 200 & 432 \\
\hline $\mathrm{Chi}^{2} / \mathrm{df}$ & 1.4 & 2 & 2.4 & 2.2 & 4.9 \\
\hline RMSEA & 0.04 & 0.08 & 0.08 & 0.07 & 0.07 \\
\hline RMR & 0.05 & 0.07 & 0.08 & 0.06 & 0.06 \\
\hline
\end{tabular}

$\mathrm{AM}=$ Angola and Mozambique; $\mathrm{B}=$ Brazil $; \mathrm{I}=$ Indonesia; $\mathrm{P}=$ Portugal; $\mathrm{O}=$ Overall.

Source: Own work.

A confirmatory factor analysis was conducted on the 15 items from the Forgivingness scale for the data from the Angolan and Mozambican samples. The model tested was the correlated three-factor model found by Chiara- mello et al. (2003). The values of the GFI and CFI indices were 0.92 , and 0.88 , respectively. The $\mathrm{Chi}^{2}$ value was $189.70\left(\mathrm{Chi}^{2} / \mathrm{df}=2.18\right)$. The RMR and RMSEA values were 0.07 and $0.06[0.05-0.08]$. 
Mean scores were computed for each of the six sub-scales, and correlation coefficients between the seeking forgiveness scales and the forgivingness scales were computed. They are shown in Table 2. Sheffé tests indicated that (a) there were no significant differences between all three lasting resentment scores (Angola-Mozambique, Brazil and Portugal), (b) the Angola-Mozambique sensitivity score $(M=4.66)$ was significantly lower than the Brazilian sensitivity score $(M=5.54), p<0.001$, (c) the Angola-Mozambique unconditional forgiveness score $(M=5.47)$ was significantly higher than the Portuguese unconditional forgiveness score $(M=4.27), p<0.001$, and (d) the Portuguese FLS score was lower than both other scores, $p<0.001$.

\section{Discussion}

The study examined the three-factor structure of the Disposition to Seek Forgiveness Questionnaire among samples from Latin America, Africa, Asia, and Southern Europe. The first hypothesis was that the three-factor structure suggested by Chiaramello et al. (2008) should hold in the samples from Brazil, Indonesia and Portugal. The data supported this hypothesis. In addition, the three-factor structure was also shown to hold in the sample from Angola and Mozambique. As a result, it seems fair to conclude that this ternary structure has cross-cultural generality.

The study also examined the three-factor structure of the Forgivingness Questionnaire among a sample from Angola and Mozambique. As this structure did not hold in a previous study on Congolese participants our question was whether this structure would hold in this new African sample. The data showed that the three-factor structure was present. The difference between the findings in the present study and the ones in the study by Kadima et al. (2001) may be explained by the difference in the composition of the samples. In this study, the Angolan and Mozambican participants were all students. In the study conducted in Congo, the participants were randomly contacted on the street, hence even though they were able to read and to respond to questionnaires, they were relatively less educated than the participants in this study.

The second hypothesis was that the pattern of relationships shown in Chiaramello et al. (2008) between the disposition to seek forgiveness structure and the forgivingness structure should also be found in the present study. The data support-

TABLE 2

Correlations between the factors in the disposition to seek forgiveness structure and the factors in the forgivingness structure, religious involvement and gender. Mean and standard deviation for the Forgivingness factors.

\begin{tabular}{|c|c|c|c|c|c|c|}
\hline \multirow[b]{2}{*}{ Factors } & \multicolumn{3}{|c|}{ Forgivingness } & \multirow[b]{2}{*}{ FLS } & \multirow[b]{2}{*}{$\begin{array}{c}\text { Religious } \\
\text { Involvement }\end{array}$} & \multirow[b]{2}{*}{ Gender } \\
\hline & LR & $\mathrm{SC}$ & UF & & & \\
\hline Inability in Seeking Forgiveness & $0.32 * * *$ & 0.11 & 0.02 & 0.08 & 0.01 & $-0.12 * * *$ \\
\hline Sensitivity to Circumstances & $0.24 * * *$ & $0.29 * * *$ & 0.11 & 0.03 & -0.02 & 0.07 \\
\hline Unconditional Seeking of Forgiveness & $-0.17 * * *$ & 0.01 & $0.3 * * *$ & $0.28 * * *$ & 0.04 & 0.01 \\
\hline Range & $0-10$ & $0-10$ & $0-10$ & $0-10$ & $0-3$ & \\
\hline M (Overall) & 2.86 & 5.15 & 4.89 & 3.94 & 2.27 & \\
\hline SD (Overall) & 1.89 & 1.91 & 1.98 & 2.3 & 0.76 & \\
\hline M (Angola and Mozambique) & 2.43 & 4.66 & 5.47 & 4.7 & 2.49 & \\
\hline SD (Angola and Mozambique) & 2.18 & 2.5 & 2.43 & 2.41 & 0.67 & \\
\hline M (Brazil) & 3.11 & 5.54 & 4.8 & 4.35 & 2.27 & \\
\hline SD (Brazil) & 2.26 & 2.26 & 2.18 & 2.13 & 0.77 & \\
\hline M (Portugal) & 2.88 & 5.27 & 4.24 & 2.88 & 2.03 & \\
\hline SD (Portugal) & 2.01 & 1.75 & 1.97 & 1.86 & 0.78 & \\
\hline
\end{tabular}

FLS $=$ Forgiveness Likelihood Scale. $* * * p<0.001$.

Source: Own work. 
ed the hypothesis. Significant correlations were observed between the corresponding factors in each structure. In other words, (a) ISF was positively associated with lasting resentment after an offense, (b) SCS was associated with the sensitivity to circumstances before granting forgiveness, (c) USF was positively associated with unconditional forgiveness and negatively associated with lasting resentment. In addition, the sensitivity to circumstances before seeking forgiveness was positively associated with lasting resentment, and the FLS score was positively associated with unconditional seeking of forgiveness.

The correlations in the present study were, however, of a lower magnitude than the correlations found in the study by Chiaramello et al. (2008). This may be explained by the fact that in the present study, the participants were about the same age, and the same educational level. However, in the study by Chiaramello et al. (2008), participants' ages ranged from 18 to 83 , and the educational levels varied. In other words, the variability between participants was lower in the present study than in the study by Chiaramello et al. (2008).

Several additional findings deserve to be commented. Firstly, the unconditional forgiveness score and the forgiveness likelihood scores were higher among the Africans (Angola and Mozambique) than among the Portuguese. These finding were consistent with the findings by Kadima et al. (2001) that Congolese people had higher unconditional forgiveness scores than French people of the same ages and gender. Secondly, SCS was higher among the Indonesians than among other groups. These finding were consistent with the findings by Suwartono et al. (2007) showing that the Indonesian sensitivity to circumstances score before forgiving was notably higher than the French.

Thirdly, ISF was lower among female participants than among male participants. This finding was consistent with the findings by Chiaramello et al. (2008); although in this study, the correlation did not reach significance. Fourthly, religious involvement was not associated with the seeking of forgiveness. This finding was consistent with the findings by Sandage, Worthington, Hight, and Berry (2000).

\section{References}

Bagnulo, A., Muñoz Sastre, M. T., \& Mullet, E. (2009). Conceptualizations of forgiveness: A Latin America-Western Europe comparison. Universitas Psychologica, 8(3), 673-682.

Basset, R. L., Bassett, K. M., Lloyd, M. W., \& Johnson, J. L. (2006). Seeking forgiveness: Considering the role of moral emotions. Journal of Psychology and Theology, 34(2), 111-124.

Chiaramello, S., Muñoz Sastre, M. T., \& Mullet, E. (2008). Seeking forgiveness: Factor structure, and relationships with personality and forgivingness. Personality EI Individual Differences, 45(5), 383-388.

Kadima Kadiangandu, J., Gauché, M., Vinsonneau, G., \& Mullet, E. (2007). Conceptualizations of forgiveness: Collectivist-Congolese versus individualist-French viewpoints. Journal of Cross-Cultural Psychology, 38(4), 432-437.

Kadima Kadiangandu, J., Mullet, E., \& Vinsonneau, G. (2001). Forgivingness: A Congo-France comparison. Journal of Cross-Cultural Psychology, 32, 504-511.

Mullet, E., Barros, J., Frongia, L., Usai, V., Neto F., \& Rivière-Shafighi, S. (2003). Religious involvement and the forgiving personality. Journal of Personality, 71(1), 1-19.

Neto, F. (2007). Forgiveness, personality and gratitude. Personality and Individual Differences, 43(8), 2313-2323.

Neto, F., \& Mullet, E. (2004). Personality, self-esteem, and self-construal as correlates of forgiveness. European Journal of Personality, 18(1), 15-30.

Roberts, R. C. (1995). Forgiveness. American Philosophical Quarterly, 32(4), 289-306.

Rye, M. S., Loiacono, D. M., Folck, C. D., Olszewski, B. T., Heim, T. A., \& Madia, B. P. (2001). Evaluation of the psychometric properties of two forgiveness scales. Current Psychology, 20(3), 260-277.

Sandage, S. J., Worthington, E. L., Jr., Hight, T. L., \& Berry, J. W. (2000). Seeking forgiveness: Theoretical context and an initial empirical study. Journal of Psychology and Theology, 28(1), 21-35. 
Seeking Forgiveness: Factor Structure in Samples from Latin

America, Africa, Asia, And Southern Europe

Suwartono, C., Prawasti, C. Y., \& Mullet, E. (2007).

Effect of culture on forgiveness: A Southern Asia-

Western Europe comparison. Personality and Individual Differences, 42(3), 513-523. 
